\title{
As rebeliões nas prisões: novos significados a partir da experiência brasileira
}

FRNANDO SALA*

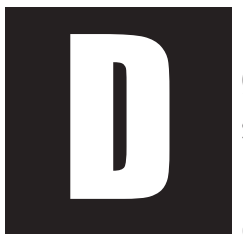

ia 18 de fevereiro de 2001, início de uma tarde de domingo. 0 sistema penitenciário do Estado de São Paulo foi sacudido pela maior rebelião já registrada na história do Brasil. Em algumas horas, 29 unidades prisionais da cidade de São Paulo, da Região M etropolitana e do Interior do Estado rebelaram-se e fizeram reféns funcionários e familiares de presos. A maior parte das prisões rebeladas integrava a Secretaria da Administração Penitenciária (SAP). 0 utras pertenciam ao sistema policial. Algumas unidades prisionais estavam previamente articuladas para este movimento e outras simplesmente foram aderindo, à medida que circulavam as informações, pela mídia, sobre a revolta. ${ }^{1}$

Esse impressionante movimento sincronizado de rebeldia foi liderado por indivíduos presos pertencentes a uma organização criminosa denominada Primeiro Comando da Capital (PCC). Milhares de espectadores acompanharam pela televisão, imagens das rebeliões que se espalharam pelos presídios do Estado. U m dos centros de comando do movimento foi a Casa de Detenção de São Paulo, com mais de sete mil presos. ${ }^{2}$

* Doutor em Sociologia e Pesquisador do Núcleo de Estudos da Violência da Universidade de São Paulo. Brasil.

$1 \mathrm{No}$ caso de algumas unidades prisionais pode-se dizer que houve mera solidariedade à rebelião ou um protesto contra as condições de encarceramento, sem que houvesse uma vinculação maior delas com o grupo organizado que dirigia a maior parte das prisões amotinadas.

2 A Casa de Detenção de São Paulo foi palco, em outubro de 1992, da morte de 111 presos, a sua maioria perpetrada por policiais na contenção de uma rebelião. 
Essas rebeliões simultâneas tinham um motivo muito claro, ligado a esse grupo criminoso: pressionar a administração penitenciária para a volta para a Casa de D etenção de São Paulo dos líderes do grupo que haviam sido removidos dali, dias antes, para o Anexo da Casa de Custódia de Taubaté, uma espécie de supermax ${ }^{3}$ do sistema penitenciário do Estado de São Paulo. Pediam os rebelados, ao mesmo tempo, a desativação do Anexo, onde as regras disciplinares eram extremamente severas, permanecendo os presos, durante 23 horas por dia, isolados na cela, sem qualquer atividade e com severas restrições de visitas. Para a opinião pública, naquele momento não foram apresentadas pelos presos denúncias de más condições das prisões, alimentação ruim, falta de assistência médica ou judiciária, arbitrariedades praticadas pelas autoridades, maus tratos, etc. Só depois de permanecerem rebeladas algumas unidades prisionais, no dia seguinte, é que as lideranças chamaram a atenção para os problemas e as deficiências do serviço penitenciário.

0 dia escolhido pelos rebelados foi estratégico para conter uma reação violenta das autoridades: domingo, dia de visitas de familiares e amigos de presos. A presença de milhares de familiares no interior das prisões tornava aflitiva a situação e colocava um desafio para as autoridades, no sentido de uma solução sem violência. Em alguns lugares, as rebeliões foram controladas ainda no domingo e, em outros, estenderam-se pela segunda-feira. 0 saldo de todo o movimento foi a morte de 20 presos, a maior parte provocada pelos próprios presos, em decorrência de conflitos entre grupos criminosos rivais.

Como foi possível um conjunto de rebeliões simultâneas de tamanha envergadura? (Provavelmente este tenha sido um dos maiores movimentos de presos, jamais visto no mundo moderno). 0 que teria provocado uma articulação tão surpreendente de tantos presos em tantas prisões? Tradicio-

3 São assim chamadas as prisões de segurança máxima-máxima que foram construídas nos EU A 
Sociologias, Porto Alegre, ano 8, no 16, jul/dez 2006, p. 274-307

nalmente a produção teórica nesta área vem explicando as rebeliões, grosso modo, de duas formas (U seem e Kimball, 1991). De um lado, a partir das possibilidades de emergência de movimentos de rebeldia por conta das privações que são impostas aos presos. Nesta vertente, as rebeliões nada mais são que formas de protesto, de inconformismo, contra a imposição de situações adversas que envolvem, por exemplo, a superlotação, a alimentação ruim, os maus tratos, etc. De outro lado, as rebeliões nas prisões podem ser explicadas, tal como outros movimentos de protesto fora da prisão, a partir do afrouxamento dos controles de toda ordem, na vida social. Essa vertente é muitas vezes acusada de conservadora, por derivar as revoltas sociais e, por conseqüência, as rebeliões nas prisões, do rompimento das condições de manutenção da ordem.

0 presente artigo tem como pressuposto as limitações de cada uma dessas duas vertentes, para compreender uma nova tendência que se apresenta nas rebeliões prisionais brasileiras desde o início dos anos 1990 e que teve como clímax a revolta de 2001. Direciona a reflexão para uma composição de elementos de cada uma delas para buscar uma compreensão mais ampla dessas rebeliões. A 'megarrebelião', como a denominou a imprensa, foi um acontecimento ímpar e, ao mesmo tempo, revelou uma nova característica presente no sistema penitenciário brasileiro, no qual a atuação de grupos criminosos influencia e, por vezes, determina profundamente as práticas quotidianas no ambiente prisional, inclusive as rebeliões, com a presença ou não das condições precárias de existência nos cárceres. A capacidade de organização demonstrada pelo grupo que liderou as rebeliões, envolvendo boa parte das 29 unidades prisionais amotinadas; a dimensão do movimento que envolveu cerca de 28 mil presos; a pauta das reivindicações; 0 uso de familiares e amigos de presos presentes num dia de visitas, e os inequívocos indicadores de corrupção por parte dos agentes do Estado que lidam com a custódia de presos sugerem alguns novos ingredientes 
para se compreender a questão, não apenas do fenômeno das rebeliões no Brasil, mas também do próprio perfil da violência presente nas prisões brasileiras. 0 evento talvez tenha sido um momento agudo numa seqüência de rebeliões que se alastraram pela década de 90 , e que coloca em questão dois aspectos: em primeiro lugar, as condições precárias de existência nos cárceres são facilmente encontradas, sobretudo naquelas destinadas aos presos provisórios, bem como a continuidade de uma série de práticas que aviltam a integridade física dos presos; em segundo lugar, a incapacidade de o Estado organizar e manter os serviços de segurança, dentro de uma agenda política que assegure alguma ordem social com o respeito à lei. Ao mesmo tempo, ocorre a constituição desses grupos como atores políticos no cenário interno das prisões, mas que tentam enraizar a sua atuação em diversas atividades da sociedade (especialmente ligadas ao mercado informal) e exercer um controle efetivo sobre parcelas consideráveis das populações pobres de muitas regiões metropolitanas.

Nos últimos dez anos, têm sido comuns as rebeliões nas prisões brasileiras que deixam um sangrento rastro de mortes entre os presos. Tais mortes não derivam da ação policial de contenção desses movimentos, mas na sua maioria são provocadas por outros presos, em função de conflitos internos, das disputas entre grupos criminosos. Assim, além de denunciarem condições precárias de encarceramento que continuam a predominar no Brasil, as rebeliões têm revelado uma baixa capacidade do Estado em controlar a dinâmica prisional, em fazer valer princípios fundamentais de respeito à integridade física dos indivíduos presos, permitindo que grupos criminosos imponham uma ordem interna sobre a massa de presos.

0 artigo procura explorar os significados da presença de grupos criminosos controlando o quotidiano prisional, impondo à massa carcerária diversas formas de constrangimento físico e moral que envolvem práticas como extorquir dinheiro mediante contribuições compulsórias para os grupos; 
Sociologias, Porto Alegre, ano 8, no 16, jul/dez 2006, p. 274-307

explorar familiares, inclusive sexualmente; transferir para outros presos a responsabilidade por crimes e infrações cometidas no interior da prisão, além de todo o controle sobre fontes de arrecadação de dinheiro dentro da prisão (comércio dos postos de trabalho, locais de habitação, tráfico de drogas, entrada e uso de celulares, compra de armas). Esta presença e atuação no controle da vida prisional por parte dos grupos criminosos promovem uma nova dinâmica de rebeliões e acomodações. A hipótese básica neste artigo é de que o Estado, representado pelo corpo dirigente local, não tem mais o controle efetivo da maioria das prisões sob sua responsabilidade, conseguindo assegurar a paz interna somente pela delegação do dia-a-dia prisional às lideranças desses grupos criminosos.

Este espetacular avanço do poder dos presos em relação às autoridades constituídas sugere um olhar retrospectivo sobre a experiência das rebeliões nos Estados Unidos e na França, desde os anos 70. Pretende-se estabelecer uma aproximação analítica desses movimentos, conservandoIhes os devidos contextos históricos, mas buscando perceber os paralelose as distâncias que apresentam a situação vivida nas prisões brasileiras e a daqueles países. É uma hipótese a ser verificada a maior capacidade do Estado, nos Estados U nidos e na França, de enfrentar sérios desafios e instabilidades em suas prisões, conseguindo conter as rebeliões, sem transferir de forma acentuada o poder para os presos. Já no Brasil, e particularmente em São Paulo e no Rio de Janeiro, as deficiências e precariedades do Estado - superlotação, número reduzido do staff, péssimas condições de habitabilidade, entre outras- geram tensões constantes, tentativas de fuga, rebeliões que vêm sendo 'administradas' através da concessão cada vez mais ampla de poder da administração para os grupos criminosos e suas lideranças. 


\section{0 percurso da reflexão sobre as rebeliões ${ }^{4}$}

A primeira onda da reflexão sociológica sobre rebeliões nas prisões apareceu, nos Estados U nidos, na década de 50. Parte da literatura que se formou naquele momento tentava entender a crise que atravessavam as prisões norte-americanas, quando entre 1950 e 1955, haviam ocorrido quase que a metade de todas as rebeliões dos últimos cem anos nos Estados Unidos (Sullivan, 1990). A eclosão dessas rebeliões era explicada por fatores que atuavam isoladamente ou em conjunto, tais como, o suporte financeiro insuficiente, indiferença pública e oficial, pessoal desqualificado, ociosidade forçada dos presos, ausência de programas profissionais, tamanho excessivo das prisões, superlotação, motivações políticas da administração prisional, práticas imprudentes (incompetentes) de livramento. Porém a constatação de tais aspectos não avançava na direção de uma compreensão mais profunda das raízes desses eventos.

Este período produziu duas obras clássicas para os estudos das prisões: The Society of Captives, de Gresham Sykes, publicado em 1958 e Asylums, de Erving Goffman, publicado em 1961. Estas análises trouxeram um aporte novo de conhecimento sobre a dinâmica prisional e, com isso, ampliaram as possibilidades de compreensão das rebeliões. Aprofundaram aspectos das relações que se estabeleciam no espaço prisional e que até então haviam sido tratados apenas de forma tangencial, como é o caso da teia de relações entre equipe dirigente e massa de internos. A dimensão inovadora dos trabalhos desses autores não ignorou a tradição de estudos prisionais já disponível nos Estados U nidos, ainda que de proporção acanhada, e que se assentava numa perspectiva de análise da prisão como um sistema social pouco permeável e marcado pela produção de uma cultura peculiar (Clemmer, 1940; Weinberg, 1942; Hayner e Ash, 1939).

4 Agradeço ao meu colega Prof. Marcos César Alvarez a leitura dos originais e os supetões. 
Sociologias, Porto Alegre, ano 8, no 16, jul/dez 2006, p. 274-307

Forte influência receberia, principalmente Sykes (1974), de autores como Donald Clemmer (1940) com seu trabalho The Prison Community, produzido no início dos anos 30, mas publicado pela primeira vez em 1940. O clássico estudo de Clemmer se voltava para a "descrição da cultura da prisão", envolvendo a constituição de uma comunidade prisional com sua estratificação social, formação de grupos informais, lideranças, costumese mecanismos próprios de controle social. No entanto, reconhecia Clemmer que a penitenciária não era uma closed culture, e nesta obra procurou explicar como se estruturavam as relações da cultura prisional com a sociedade abrangente. Sykes (1974:xiii) considerou aquela obra um dos mais profundos estudos sociológicos sobre as prisões norte-americanas. 0 refinamento da análise de Sykes em relação à eclosão das rebeliões como momento de fratura no equilíbrio nas relações entre presose custodiadores, tem inspiração na análise minuciosa que fez Clemmer da cultura prisional.

Embora Sykes (1974) não tenha formulado um conceito de rebelião, ele indicou que este tipo de movimento decorria de um desequilíbrio no sistema de relações de poder estabelecidas entre a equipe dirigente e os presos. Para ele, a prisão oficialmente detém todas regras, e a administração, em tese, exerce o controle total sobre o seu funcionamento. Porém a gestão do cotidiano prisional requer um jogo de concessões entre o grupo dirigente e os presos. Não é possível, diz Sykes, fazer cumprir todas as regras sem que haja colaboração por parte dos presos, cooperação que é barganhada por favores e permissões. Há uma tensão freqüente entre os presos e os funcionários. Sykes sugere, portanto, que a partilha do poder pode manter-se equilibrada, mas pode ocorrer também que diversos mecanismos de acomodação entre presos e funcionários se esgotem na direção de um acirramento de conflitose de busca por ampliação de poder de um grupo ou de outro. As rebeliões, para ele, seriam esses momentos agudos em que há uma crise nesta distribuição de poder, um aprofundamento das 
tensões, que provocam uma recomposição das relações entre os dois grupos. É por isso que Sykes rejeita as leituras de que as rebeliões sejam acontecimentos explosivos e provocados por detonadores imediatos. Para ele, as rebeliões decorrem deste processo mais profundo e de longa duração no equilíbrio de poder. As tensões encontram na rebelião um momento crítico de solução, muitas vezes uma tentativa de reação dos presos à reconquista do poder pela equipe dirigente.

No início dos anos 1970, os Estados U nidos apresentaram um estrondoso boom de rebeliões que tiveram forte ligação com as reivindicações do movimento negro e dos grupos de ativistas dos movimentos pelos direitos civis, oriundos da década de 60. A rebelião de Ática (1971), com 43 mortos, e a rebelião na prisão do Novo M éxico (1980), com 32 mortos, foram duas das maiores rebeliões nos Estados U nidos, que provocaram a emergência de uma segunda onda de estudos. U ma das obras mais importantes foi a de Bert U seem and Peter Kimball (1991), que aparece em 1989 e que analisa diversas rebeliões, sustentando como argumento principal que tais movimentos no final da década de 60 e nos anos 70, encaixavam-se no contexto dos conflitos sociais mais amplos daquele período. As rebeliões dentro das prisões seriam desdobramentos desse movimento de revolta que explodia nas ruas.

Com isso, o modelo de explicação das rebeliões de Sykes, fundado numa ótica da prisão como um sistema de poder fechado em si mesmo, polarizando os conflitos entre presos e equipe dirigente, mostrava suas limitações com a explosão das rebeliões nos Estados U nidos naquele período, uma vez que indicavam a forte conexão dos movimentos pelos direitos civis. Mesmo depois, já nas décadas de 80 e 90, as rebeliões naquele país foram atravessadas por novos componentes que também enfraquecem a argumentação de Sykes. A presença de conflitos entre gangse grupos criminosos, baseados em bairros e etnias, tem sido constante e é responsável 
Sociologias, Porto Alegre, ano 8, no 16, jul/dez 2006, p. 274-307

por muitas rebeliões em que os presos procuram acertar uma forma de acomodação entre esses grupos na convivência prisional, mais do que estabelecer uma relação de poder direta com a equipe dirigente.

Num trabalho anterior, Useem e Kimball (1987) haviam mostrado que as rebeliões prisionais variavam muito na forma em que ocorriam, quanto à existência, ou não, de reféns, quanto aos tipos de manifestos expedidos pelos presos, quanto à existência de organização interna da parte dos presos, quanto ao tipo de pilhagens, etc. Segundo eles, tradicionalmente os sociólogos têm tentado explicar as rebeliões como uma ação coletiva que decorre de aspectos estruturais: privação econômica, recursos disponíveis para o grupo, táticas perseguidas pelo grupo, existência de organização. Embora esta ênfase nos aspectos estruturais tenha sido importante para pôr de lado teorias que viam nesses movimentos manifestações instintivas de violência dos presos, derivadas de sua "natureza humana", os autores propõem que a ênfase seja dada às teorias sociopsicológicas, que consigam articular os aspectos psicológicos com as questões estruturais, sem, no entanto, transformar aqueles em mero reflexos destas. Propõem que as rebeliões sejam pensadas a partir de uma teoria da ação coletiva que considere a importância dos aspectos tanto estruturais como dos aspectos psicológicos. N este sentido, a hipótese central de seu trabalho é que as variações na forma de manifestação das rebeliões estão relacionadas à articulação entre esses dois eixos. Sugerem também que a identificação entre os presos seja a variável independente que explique alguns aspectos das rebeliões prisionais como a sua intensidade, nível de violência e o comportamento dos revoltosos. (U seem and Kimball, 1987:88)

Partindo destes pressupostos e analisando várias rebeliões nos Estados Unidos, U seem e Kimball adicionam uma importante contribuição para o conhecimento das variações nos tipos de rebelião. Sua análise amplia o antes acanhado campo das explicações relacionadas às privações econômi- 
cas ou então à dinâmica das relações de poder, em direção de um conhecimento mais detalhado do mecanismo de construção das identidades entre os presos para a eclosão desses movimentos e para o seu envolvimento, ou não, com eles. A variedade nas formas que assumem as rebeliões não é passível de explicação apenas pelas disposições dos presos (os processos que envolvem o nível da micromobilização devem ser estudados para se entender porque determinadas preferências acabam resultando em ação), mas também pelas características da instituição, pelas formas de atuação do staff, pelos esquemas internos de segurança, etc. que são aspectos igualmente importantes na produção de um distúrbio ou de uma rebelião.

$\mathrm{Na}$ Europa, em vários países como a França, Inglaterra e Itália, neste mesmo início dos anos 1970, também explodiram movimentos de rebeldia nas prisões (Artières, 2003; Favard, 1981 e 1987; Adams, 1994). As revoltas na França, em 1970, não podem ser dissociadas da presença de militantes políticos que passavam a existir nas prisões em decorrência da efervescência política naquele período. Neste sentido, os movimentos que ocorrem na França também guardavam estreita relação com os movimentos políticos externos às prisões, à semelhança do que se constata nos Estados Unidos. No entanto, depois, esses movimentos nas prisões francesas se alastraram e envolveram não apenas os presos políticos, mas também outros presos e outras reivindicações (Artières, 2003).

Jean Favard (1981) não faz uma clara distinção entre movimentos coletivos e rebeliões, nem destaca as relações entre alguns desses movimentose suas tramas políticas na sociedade francesa, mas observou que os tais movimentos nas prisões francesas vinham ocorrendo com certa regularidade já nos anos 60, embora tenha sido a partir de 1971 que se tornaram mais intensos, atingindo, naquele ano, o número de 37 (1981: 176). U ma verdadeira crise nas prisões francesas tem início com a agressão de um preso a um surveillant em 27 de julho daquele ano, em Lyon, que vai 
Sociologias, Porto Alegre, ano 8, no 16, jul/dez 2006, p. 274-307

provocar a sua morte um mês depois. A crise se aprofunda quando em 21 e 22 de setembro um outro surveillante uma enfermeira, depois de serem tomados como reféns por dois presos são mortos em Clairvaux. Atendendo às pressões dos sindicatos penitenciários, o ministro da Justiça, René Pleven, em 12 de novembro proíbe o envio de todos os presentes de $N$ atal para os presos. Dois movimentos de revolta de presos em Toul, em dezembro, provocaram uma reação do governo que criou uma comission d'enquête presidida por Schmelck, um antigo diretor da administração penitenciária. A publicação do relatório da comissão ainda no início de 1972 não conteve a agitação nas prisões francesas, que naquele ano, subiram a 85 movimentos (Favard, 1981: 177). Embora se tenham reduzido no ano seguinte para 36 movimentos, em 1974 há uma explosão de revoltas, atingindo o número de 152 em 77 estabelecimentos. Houve uma intensa concentração de movimentos entre o final de julho e começo de agosto: seis presos morreram e grandes foram os prejuízos aos estabelecimentos. N os anos seguintes, os números destes incidentes caíram: em 1975 foram 36, em 1976, 48, em 1977, 39 e em 1978, 38, sendo que a maior parte desses movimentos não exigiu uma presença das forças da ordem para sua contenção.

Favard ainda observa que as revoltas, nesse período, tinham características diversas tanto no que diz respeito às causas que as provocavam, aos seus integrantes, como também aos objetivos buscados e aos resultados obtidos. Assim, algumas envolviam a recusa da alimentação ou a recusa na realização das atividades de trabalho. Em geral, eram movimentos que revelavam uma situação de conflito, mas que explodiam subitamente, sem qualquer previsibilidade (1981: 181). 0 que chama a atenção nesses movimentos na França entre 1971 e sobretudo em 1974, é a "ação coletiva se desenvolvendo ao mesmo tempo em vários estabelecimentos" (Favard, 1981: 182).

De certo modo, as rebeliões nesse período teriam sido provocadas, segundo Favard, muito mais em função da precariedade dos serviços prisionais, como alguns estabelecimentos estarem envelhecidos, outros terem 
estruturas de funcionamento rígidas e arcaicas, sem pessoal em número suficiente para as novas tarefas administrativas que iam aparecendo e mesmo a superlotação em alguns deles. Favard ainda observa que, depois de 1974, os movimentos refluem, e uma legislação restritiva em 1978 favorece a intervenção da polícia nos motins para manter a ordem.

De qualquer forma, o refluxo das rebeliões nas prisões francesas nas décadas seguintes parece indicar que o Estado promoveu intervenções legais e institucionais que foram capazes de impor uma ordem no interior dos estabelecimentos e de inibir os principais fatores que motivaram os movimentos de revolta. Por certo que contribuíram com este declínio o esfacelamento dos grupos políticos e de suas ações que motivaram a presença de militantes nas prisões.

Robert Adams (1994), num dos mais audaciosos estudos comparativos entre as rebeliões nos Estados U nidos e Grã-Bretanha, reitera o ponto de vista de U seem e Kimball ao afirmar que

o final dos anos 60 e o início dos anos 70 viram um perío do de crescimento da solidariedade e da consciência política entre os presos nas rebeliões prisionais. A rebelião na prisão de Ática é o ponto alto nisso que alguns comentadores chamaram de 'guerras de libertação', na qual a organização dos presos foi notável (Adams, 1994, p. 76).

Porém a contribuição mais interessante de Adams para a presente reflexão diz respeito ao conceito que ele denomina de rebelião prisional. Rejeita a leitura de que as rebeliões são erupções quase sempre violentas, sem alvo, cujo significado principal é confirmar a insensatez dos presos envolvidos. Para ele, estes movimentos são parte da estratégia de resistência dos presos em relação a algum aspecto do seu encarceramento. Desta forma, as rebeliões poderiam ser entendidas, ou como parte da discussão mais ampla sobre a violência e indisciplina dos presos, ou então como uma instância de atividade coletiva, mesmo política, ainda que ilegal, dos presos. 
Sociologias, Porto Alegre, ano 8, no 16, jul/dez 2006, p. 274-307

Adams propõe que as rebeliões, para serem caracterizadas como tais, apresentem os seguintes aspectos: a) elas são parte de um continuum de atividades (ou seja, não são aberrações); b) envolvem discórdia e/ou protesto. Elas fazem parte de um amplo leque de formas de manifestação que inclui revoltas, conflitos, ocupações, greves, protestos, envolvendo indivíduos e grupos; c) elas envolvem uma interrupção no funcionamento da prisão; d) os presos tomam uma prisão completamente, ou parte dela (seus recursos, regime ou staffing). Isso significa que podem ocorrer de modo direto, material, por meio de uma ocupação, de barricadas, etc. ou por meio de uma tomada de reféns. Mas pode ser de uma forma simbólica, como uma manifestação de barulhos feitos pelos presos dentro das celas em protesto contra alguma coisa; e) elas são temporárias, geralmente são eventos que duram pouco tempo; f) envolvem grupos de presos. Segundo 0 autor, é difícil justificar que um movimento com menos de 5 presos possa ser encarado como uma rebelião, ou seja, para o autor, são sempre ocorrências coletivas; g) elas são direcionadas para obter mudanças ou para expressar queixa.

A partir destes elementos, Adams sugere que uma rebelião seja definida como

parte do contínuo de práticas e relacionamentos inerentes ao encarceramento, que envolvem atividades de dissensão e/ou protesto por parte de indivíduos ou grupos de presos que interrompem seu encarceramento, por meio do qual tomam em todo ou em parte os recursos da prisão e expressam uma ou mais queixas ou uma demanda por mudanças ou as duas coisas. (Adams, 1994, p.13-14)

5 "part of the continuum of practices and relationships inherent in imprisonment, which involves dissenting and/or protesting activities by individuals or groups of prisoners which interrupt their imprisonment, by means of which they take over all or part of the prison resources and either express one or more grievances or a demand for change, or both" (Adams, 1994, p.13-14). 
Esta interessante definição coloca em destaque o ponto central que cabe aqui aprofundar em relação à experiência das rebeliões nas prisões brasileiras, ou seja, tal como as concepções de Sykes, U seem e Kimball, Adams também dá grande destaque para as rebeliões enquanto movimentos de hostilidade dos presos em relação ao 'poder estabelecido'. As rupturas provocadas pelas rebeliões implicam recomposição das relações de poder entre custodiadores e internos, demandas dos presos em relação à deficiência nos serviços, redistribuição de recursos, etc. Mas o que se pretende mostrar aqui é que as rebeliões não precisam sempre atender a estes tópicos, e que no Brasil a partir dos anos 90, vêm crescendo as rebeliões que não preenchem 0 item $g$ proposto acima por Adams, ou seja, não apresentam queixa para a administração e não apresentam necessariamente uma proposta de mudança, mas são movimentos que reorganizam 0 poder entre os grupos criminosos presentes na massa carcerária e sobre os quais a administração tem um controle bastante limitado. Assim, desde os anos 90, as rebeliões no Brasil têm sido provocadas, muitas vezes, a partir de disputas entre grupos organizados que usam a rebelião como instrumento de desordem para acertos de contas, para matar lideranças rivais, para vingar mortes de companheiros em outras prisões e para repactuar as relações entre os grupos criminosos e, por vezes, entre eles e o staff.

Esta hipótese é possível de ser sustentada quando se considera que, no Brasil, o Estado não tem sido capaz de assegurar os requisitos básicos para o encarceramento dos indivíduos. 0 s presos, independentemente de sua periculosidade, idade, reincidência, tipo de crime, são recolhidos em estabelecimentos, em geral, lotados, em condições sanitárias ruins, mantidos misturados desde o período em que permanecem no aguardo do julgamento até o período pós-julgamento. ${ }^{6} \mathrm{~A}$ maior parte dos presosé provenien-

60 sindivíduos portadores de título de ensino superior, no Brasil, quando detidos e durante o período em que aguardam julgamento têm direito a permanecerem em cela individual. 
Sociologias, Porto Alegre, ano 8, no 16, jul/dez 2006, p. 274-307

te das camadas pobres da população, o que significa que eles não têm defensores ou mesmo qualquer suporte social. Ao mesmo tempo, o Estado não assegura condições elementares de encarceramento, como a assistência jurídica, social, médica, os materiais de higiene, uniforme e até mesmo alimentação. Esta precariedade nos serviços prestados estimula a rede de solidariedade entre os presos e coloca muitos deles na dependência dos grupos criminosos bem organizad os e que mobilizam recursos para 0 atendimento das necessidades de seus integrantes, como advogados, apoio à família (por exemplo, para o transporte dela até a prisão, remédios, assistência médica, empréstimos, etc.).

$E$, neste sentido, é crucial a questão levantada por U seem e Kimball com relação à identificação dos indivíduos na sua participação em rebeliões. 0 que parece estar em curso nas prisões brasileiras não é apenas uma identidade genérica dos presos 'contra' a administração, mas também e principalmente a atuação de grupos criminosos que promove uma forte identidade e fidelidade de seus integrantes e que soluciona as dissidências e disputas por meio de rebeliões e, em geral, de mortes de integrantes do grupo rival.

\section{Um rio de sangue: as rebeliões no Brasil}

As rebeliões nas prisões brasileiras tornaram-se objeto de maior preocupação dos estudos acadêmicos quando, no início dos anos 1980, o País começou a recuperar a normalidade democrática, depois de quase duas décadas de ditadura militar. Apesar disso, não foram muito numerosos os trabalhosque apareceram, valendo mencionar o de Edmundo Campos (1987), da Fundação João Pinheiro de M inas Gerais (1984) e de Paulo Sérgio Pinheiro (1986), que, no entanto, não tinham como foco principal as rebeliões nos presídios. U ma reflexão específica sobre as rebeliões só apareceria no início dos anos 90 com o trabalho de Eda Góes (1991), que analisou a 
emergência desses movimentos no Estado de São Paulo, no contexto da transição do autoritarismo para a democracia, nos anos 1980.

Todos esses trabalhos discutiram o papel das agências de controle social - mais particularmente, a polícia e as prisões - a partir da preocupação com os direitos humanos e a implementação de um governo democrático. Acusadas de herdeiras da tradição autoritária que se exacerbou durante a vigência da ditadura (1964-1984), aquelas agências foram desafiadasa imprimir nova orientação à sua forma de atuação, como foi o caso da política de humanização dos presídios, ou então, com as propostas de reforma dos aparelhos policiais. Foi neste contexto que Góes examinou as rebeliões como uma espécie de reação conservadora contra a introdução de medidas liberalizantes que pareciam assegurar os direitos dos presos e restringir a capacidade dos agentes do Estado em manter a ordem e a disciplina no interior dos presídios.

O Brasil, desde os anos 1980, está acompanhando uma tendência de crescimento da criminalidade, que se manifesta em vários países e traz como conseqüência o aumento expressivo das populações encarceradas, a partir de uma percepção de que políticas penais mais severas devam ser implementadas para conter aquela criminalidade. Loïc Wacquant (1999) sugere que 0 encarceramento foi retomado e aprofundado nos Estados Unidos, a partir dos anos 1970 como um dos principais mecanismos de controle das massas humanas, privadas dos benefícios que, até então, 0 Estado-providência garantia. Ao desmonte que vai ocorrendo na estrutura desse tipo de Estado, corresponderia um avanço naquilo que ele denomina estado penal (Wacquant, 1998; 1998b). A criminalização da miséria, a repressão às ilegalidades e estratégias de sobrevivência das camadas pobrese o combate ao tráfico de drogas compõem os principais ingredientes que explicam a explosão nas taxas de encarceramento em praticamente todos os países do mundo ocidental. 0 Brasil parece representar um bom exemplo desta linha de análise. 
Sociologias, Porto Alegre, ano 8, no 16, jul/dez 2006, p. 274-307

Tabela 1-População encarcerada e taxa por 100 mil habitantes Brasil, 19882003

\begin{tabular}{l|c|c}
\hline & Presos & Taxa 100 mil \\
\hline 1988 & 88.041 & 65,2 \\
1993 & 126.152 & 83,2 \\
1995 & 148.760 & 95,4 \\
1997 & 170.207 & 108,6 \\
2000 & 211.953 & 134,9 \\
2002 & 248.685 & 146,5 \\
2003 & 308.304 & 181,5 \\
\hline
\end{tabular}

Fonte: Ministério da Justiça

O s dados da tabela acima mostram o acentuado incremento da população encarcerada no Brasil na década de 1990 e particularmente um vertiginoso aumento no início dosanos 2000 . Isto trouxe o agravamento das condições de vida nas prisões,e seus principais componentes são: a superlotação de muitos estabelecimentos, a manutenção de práticas de torturas e maus tratos, a eclosão de rebeliões, a exigüidade dos serviços prisionais (alimentação, asseio e higiene pessoais, vestuário, assistência jurídica, programas de reabilitação, etc.), além da presença cada vez mais intensa de grupos criminosos no interior das prisões (Adorno, 1991 e Salla, 2001).

No Brasil, a pequena produção de análises sociológicas sobre as prisões e estes movimentos (Souza, s.d.; Paixão, 1985 e 1987; Fisher e Adorno, 1987; Fisher, 1989; Goes, 1991; Salla, 1999 e 2000) tem dificultado a elaboração de uma periodização das rebeliões no País e um agrupamento das ocorrências por características e tendências. Adams (1994), por exemplo, fez uma periodização para as rebeliões nas prisões norte-americanase britânicas. Em relação às prisões norte-americanas, ele dividiu as rebeliões em quatro períodos: até 1929 , as revoltas dos presos se destinam a escapar ou enfrentar os rigores disciplinares das prisões; de 30 a 50 predominam as 
rebeliões que protestam contra as precárias condições dentro das prisões; do início dos anos 50 até a metade dos anos 70 há um número crescente de rebeliões com uma consciência coletiva maior dos presos, que realizam protestos inclusive contra a própria ideologia da reabilitação. De meados dos anos 70 até o começo dos anos 90 , as rebeliões têm um caráter cada vez mais fragmentado (ele chama este período de pós-reabilitação) e alvos mais difusos.

Pode-se sugerir que, no Brasil, as rebeliões sejam agrupadas em três grandes períodos. 0 primeiro deles abrange a história das prisões brasileiras até o início dos anos 80 do século XX. A característica principal das rebeliões que explodem neste longo período é a reação à precariedade das condições de encarceramento, envolvendo a alimentação, habitabilidade em geral, os maus-tratos. 0 segundo período compreende a década de 80 e culmina com o Massacre do Carandiru, na Casa de Detenção em São Paulo, em outubro de 1992, quando o País saía do regime autoritário, e a democratização provocava uma política de humanização dos presídios, que enfrentou forte resistência dentro das administrações penitenciárias e policiais. 0 terceiro período envolve os movimentos posteriores ao Massacre do Carandiru e que se estendem aos dias de hoje, fortemente marcados pela incapacidade ou omissão do Estado em gerenciar o sistema prisional de modo a conter a atuação de grupos criminosos. Esta classificação indica a prevalência de determinado tipo de rebelião, mas não exclui a ainda constante eclosão de movimentos que explodem, motivadas pelas precárias condições de encarceramento.

Para se compreender o perfil das rebeliões contemporâneas, é essencial uma análise rápida sobre as rebeliões que emergem na década de 80 do século XX, em meio ao processo de redemocratização do País. Setores políticos ligados ao regime militar e autoritário reagiram severamente à política democrática que se implantava no país e que procurava alcançar o 
funcionamento das polícias e do sistema penitenciário. ${ }^{7}$ Neste tentava-se implantar a chamada política de humanização dos presídios com amplo respeito aos direitos humanos dos presos. A reação a essa política viria de diversas maneiras, na imprensa, no Parlamento, mas também no próprio quotidiano do sistema penitenciário do Rio de Janeiro e de São Paulo, por meio do enfrentamento do staff de segurança e administrativo em relação ao comando político. Além disso, tais setores usaram as rebeliões como estratégias de desestabilização política, sendo coniventes com os movimentos dos presos, instigando motins, semeando a desordem nas prisões.

U ma característica importante das rebeliões nesse período é que elas foram tratadas pelas forças policiais de intervenção, com extrema violência, o que acabava redundando num elevado número de presos mortos. No estado de São Paulo, apesar da democratização política em 1986, uma rebelião na Penitenciária de Presidente Wenceslau, havia feito 18 reféns, e os presos buscavam fugir do presídio. Houve intervenção das forças policiais e, mesmo depois de contida a rebelião, 13 presos foram mortos por policiais militares ou agentes de segurança do presídio, por espancamento através de canos de ferro ou de pedaços de pau. 0 utra intervenção violenta na contenção de uma rebelião se deu em julho de 1987, na Penitenciária do Estado na cidade de São Paulo. Os presos se rebelaram, estavam com duas armas de fogo e tinham vários reféns entre presos e funcionários. 0 grupo que liderava a rebelião queria a fuga do presídio. A ação de contenção foi feita pela Polícia Militar e deixou um rastro de 29 mortes. Um funcionário foi morto pelos presos. Em fevereiro de 1989, ocorreu no $42^{\circ}$. Distrito Policial em São Paulo a morte de 18 presos por asfixia dentre os 51 que haviam sido confinados pelos policiais de plantão numa cela de $1,5 \times 4 \mathrm{~m}$ sem ventilação. A medida havia sido uma represália dos policiais por causa

7 No Brasil, cada estado que compõe a federação é responsável pela organização de sua polícia judiciária e de uma polícia militar que realiza o policiamento ostensivo. 0 mesmo ocorre com o sistema penitenciário, também atribuição dos estados. 0 governo federal tem competências restritas sobre essas instituições e em geral exerce um papel de distribuidor de recursos financeiros para os estados, sem dispor de instrumentos eficazes de controle sobre o desempenho técnico e administrativo do sistemas policial e penitenciário dos estados. 
de uma tentativa de fuga seguida de um amotinamento. Essas ações desastrosas de contenção de rebeliões e tentativas de fuga atingiram o seu ápice em outubro de 1992, no chamado Massacre do Carandiru, quando 111 presos morreram na Casa de Detenção de São Paulo, 103 deles, em razão da intervenção da Polícia Militar que foi chamada para invadir o presídio e conter uma rebelião.

O ciclo seguinte de rebeliões, que vem depois do Massacre do Carandiru apresenta uma mudança importante no perfil desses movimentos. Ainda são freqüentes, assim como no período anterior, as rebeliões que se voltam contra as precárias condições de encarceramento. Há também motins que, por vezes, são contidos com emprego excessivo da força, mas a característica que passa a ser cada vez mais presente nestes eventos, sobretudo nos principais estad os e centros urbanos do País, é a atuação de grupos criminosos organizados, como responsáveis pelas rebeliões. A maior parte das mortes entre os presos não é mais o resultado da intervenção das forças policiais, mas dos conflitos entre presos. Fenômeno que só se tornou possível a partir da expressiva conivência ou ausência dos agentes do Estado no exercício do controle direto sobre a dinâmica prisional. A disputa pelo controle sobre a massa carcerária bem como o controle sobre as atividades ilegais dentro das prisões, as reivindicações destinadas a proteger os membros e principalmente as lideranças desses grupos são aspectos cada vez mais presentes nas rebeliões. Boa parte da vida carcerária nas prisões brasileiras é controlada pelos próprios presos, como, por exemplo, as celas em que irão habitar os recém-chegados, que tarefas realizarão ali, nos paviIhões ou mesmo em oficinas de trabalho. São as lideranças que escolhem muitas vezes os presos que irão trabalhar nesta ou naquela oficina, na cozinha, na lavanderia e assim por diante. É fácil imaginar que esse controle sobre espaços e atividades gera a imposição de todo tipo de constrangimento aos presos como, por exemplo: contribuições financeiras, doação de alimentos, colaboração com as atividades ilegais dentro e fora da prisão, envolvendo muitas vezes os próprios familiares dos presos. 
Sociologias, Porto Alegre, ano 8, no 16, jul/dez 2006, p. 274-307

M uitas rebeliões são desdobramentos de fugas frustradas. É um recurso de negociação do qual lançam mão os presos que tentam a fuga e não conseguem, procurando evitar a imposição de penalidades para a infração cometida. 'Virar a casa', ou seja, provocar uma rebelião, é também uma forma de criar um caos momentâneo que permita ampliar as chances de fuga. Líderes de grupos criminosos, envolvidos com tráfico de drogas, roubo de cargas, assalto a bancos, seqüestros, com freqüência conseguem fugir das prisões brasileiras contando com a rede de ilegalidades e de corrupção existente nestes estabelecimentos. Assim, conseguem subornar guardas, obter celulares, armas, planejar a fuga contando com apoio externo e interno. Tudo sugere que passou a ser uma estratégia de gerenciamento das prisões deixar que o quotidiano seja administrado pelos própriospresos, por suas lideranças, que são sempre construídas a partir do prestígio adquirido nas atividades criminosas. 0 Estado em geral não se tem considerado responsável pelos problemas decorrentes desta estratégia como as mortes de presos e conta sempre com a ausência ou incapacidade de familiares de presos mortos o processarem em busca de indenizações. Não reconhece quando há problemas de superlotação, maus tratos, e atribui as rebeliõese mortes a 'acertos de contas' entre grupos rivais.

Cabe, no entanto, listar alguns eventos que nos últimos anos têm mostrado que o controle do quotidiano prisional pelo Estado é cada vez mais precário e como as rebeliões são motivadas, muitas vezes, não pelo enfrentamento com ele, pela demanda de reivindicações. Pode-se apontar que, para este último período que se estende aos dias atuais, o modus operandi dos grupos criminosos para efetivar o seu controle sobre a massa carcerária tem sido preferencialmente a eliminação física de seus rivais em processos bastante violentos que envolvem rebeliões como oportunidades, não para a reivindicação de qualquer benefício para a massa carcerária, mas para alcançar os desafetos e destruí-los em rituais carregados de simbolis- 
mo. O utro caminho é o da obtenção de lealdades pela 'oferta' de proteção, pela ameaça, ou então pela partilha nos dividendos das atividades criminosas.

Em São Paulo, na Penitenciária Feminina da Capital, nos dias 24 e 25 de agosto de 2004, houve uma rebelião que durou cerca de 24 horas e que teve como motivação principal a eliminação de duas presas que haviam chegado àquele presídio 15 dias antes. Eram duas presas cujos maridos são considerados dissidentes de uma facção criminosa (PCC, mencionado acima) e que deveriam ser eliminadas. A 'ordem' para a execução teria vindo da vizinha Penitenciária do Estado, masculina. As presas rebeladas não conseguiram pegar as duas que desejavam, mantiveram várias funcionárias reféns e mataram uma presa que tinha problemas mentais e era considerada muito falante pelas demais presas. $N$ ão houve a apresentação de qualquer pauta de reivindicação para as autoridades quanto às condições de encarceramento.

No Rio de Janeiro, entre 29 e 31 de maio de 2004, na Casa de Custódia de Benfica, uma unidade que tinha entrado em funcionamento havia poucos meses e não apresentava superlotação, membros de uma facção criminosa chamada Comando Vermelho tentaram fugir da prisão. U m grupo de 14 presos conseguiu este objetivo, mas outros foram contidos. U ma vez frustrada a fuga, eles invadiram uma ala da prisão que abrigava membros de um grupo rival (Terceiro Comando). Vinte e quatro pessoas ficaram reféns, e 30 presos foram mortos no conflito entre asfacções, além de um agente penitenciário. Alguns presos foram decapitados e esquartejados. Em quase todas as prisões do Rio de Janeiro, membros de facções opostas tinham sido colocados em alas dentro dos mesmos presídios, provocando uma situação explosiva. Mesmo assim, diante das trinta mortes em Benfica, o subsecretário da Segurança, Marcelo Itagiba, disse que 
Sociologias, Porto Alegre, ano 8, no 16, jul/dez 2006, p. 274-307

O Estado não pode e não deve ser responsabilizado quando facínoras cometem crimes contra outras pessoas. Quem tem que ser responsabilizado, por meio de inquérito criminal, são os bandidos que cometeram esses crimes violentos. ${ }^{8}$

Apesar desse sangrento acontecimento, no presídio Ary Franco, também no Rio, no dia 3 de agosto de 2004, oito presos foram mortos por outros colegas num suposto acerto de contas. 0 s presos tomaram agentes penitenciários como reféns, invadiram as celas dos desafetos e os mataram a pauladas e estocadas.

U ma longa rebelião teve início no dia 15 de abril de 2004, na Casa de Detenção José M ário Alves, conhecida como U rso Branco, em Rondônia no norte do Brasil. Dois presos foram mortos por companheiros e, em seguida, a rebelião estourou. Cerca de 170 familiares presentes no presídio ficaram como reféns. No dia 22, o saldo das mortes entre os presos era de quatorze. Vários decapitados e um esquartejado. 0 presídio, que tinha capacidade para 350 presos, abrigava 1300.0 presídio foi completamente destruído. No curso da rebelião, os presos denunciaram a má qualidade da alimentação e queriam a mudança da administração do presídio. Aslideranças identificavam-se com uma faç̧ão criminosa de São Paulo, embora as autoridades vissem como remotas as possibilidades de uma conexão entre os grupos de criminosos de estados distantes. Cento e sessenta presos, mantidos numa ala chamada de 'seguro', eram ameaçados de morte pelos companheiros, mas não foram alcançados por eles na rebelião. ${ }^{9}$ Esta mesma prisão já tinha sido o palco de outra sangrenta rebelião no primeiro dia de janeiro de 2002 e havia provocado a morte de 27 presos. Desde 2001, já haviam sido mortos, ali naquele presídio, 64 presos. ${ }^{10}$

8 Jornal Folha de S. Paulo, de 3 de junho de 2004

$9 \mathrm{Em}$ geral, estão nesse tipo de ala existente em quase todos os presídios os presos que cometeram crimes sexuais, crimes contra crianças, mas também os que são integrantes de grupos rivais aquele que predomina numa determinada prisão.

10 Para outras informações sobre mortes de presos no Rio de Janeiro ver Caldeira (2004) 
A transferência de um grupo de presos da prisão de Puraquequara, em Manaus, no Estado do Amazonas, para uma unidade policial teria sido o motivo para uma rebelião que durou quatorze horas em junho de 2003, e que provocou a morte de 13 presos. Apesar de novo, o presídio já havia passado por outras duas rebeliões. $\mathrm{Na}$ agenda de reivindicações estava a volta do grupo de presos transferidos, maior tempo de banho de sol e a troca da direção. Cinqüenta e duas pessoas foram mantidas reféns entre funcionários e visitantes.

Ainda no ano de 2002, várias ocorrências provocam a morte de dezenas de presos. Em maio, no dia 25, foram 13 os mortos na Penitenciária Anísio Jobim, em Manaus (AM), mortes provocadas pelos próprios presos. No dia 28 de setembro, outros 11 presos morrem na cadeia pública de Embu (SP). Por fim, noticiava a Folha no dia 12 de novembro, "Rebelião de presos deixa saldo de 10 mortes", desta vez na Penitenciária Mário de Moura Albuquerque, em Franco da Rocha, na região metropolitana de São Paulo.

Embora as facções criminosas mais antigas e poderosas que atuam nas prisões se tenham formado nos estados do Rio de Janeiro (Comando Vermelho, Amigos dos Amigos, Terceiro Comando) e São Paulo (Primeiro Comando da Capital, Comando Democrático da Liberdade, Comando Revolucionário Brasileiro da Criminalidade), por todo o Brasil esses grupos têm surgido nas prisões. É o caso de estados como o Rio Grande do Sul (M anos e Brasas), Mato Grosso do Sul (Primeiro Comando da Liberdade), Minas Gerais (Primeiro Comando M ineiro, Comando M ineiro de O perações Criminosas), Paraná (Primeiro Comando do Paraná), Pernambuco (Comando Norte/N ordeste), entre outros. É provável que esses grupos não tenham ainda a mesma consistência dos existentes no Rio e em São Paulo, mas não é difícil prever que sua atuação encontra condições favoráveis para se expandir. 0 jornal Folha de S. Paulo, ao comentar a presença desses grupos, ${ }^{11}$

11 Ver dia 6 de julho de 2004 a matéria 'Presos criam facções fora do eixo Rio-SP', p. C-3. 
Sociologias, Porto Alegre, ano 8, no 16, jul/dez 2006, p. 274-307

atribuía o surgimento de vários deles ao contato com os líderes de facções do Rio e de São Paulo que foram transferidos para esses estados e que teriam incentivado e ajudado a criação desses grupos. A precariedade das condições de encarceramento da maior parte das prisões e as possibilidades de atuação dos grupos criminosos no cotidiano prisional facultada pela limitada capacidade de controle do Estado, encontram-se na base da proliferação desses grupos, das rebeliões e mortes violentas nas prisões brasileiras.

O governo federal fez aprovar no Congresso $\mathrm{N}$ acional, em dezembro de 2003, uma lei (n. 10.792) que regulamenta o chamado Regime Disciplinar Diferenciado (RDD). Por esta lei, presos que provoquem rebeliões, atos de indisciplina podem ser mantidos até 360 dias em presídios ou alas especiais de presídios, confinados 22 horas por dia em celas individuais, sem atividades e com severas restrições de visitas. Este é o principal mecanismo que o governo tem utilizado para conter a atuação destas lideranças. Esse sistema já vinha sendo utilizado no Estado de São Paulo, e a imposição destes rigores provocou a emergência da 'megarrebelião' mencionada na abertura deste texto. Se, de um lado, este regime expõe uma dimensão repressiva, de outro, também produz novos elementos de poder e status. A passagem de presos por estes estabelecimentos de regime severo os investe de maior respeito e prestígio junto à massa carcerária, empoderando ainda mais as lideranças do crime organizado.

Tem havido fortes reações contrárias a esse regime, tanto da parte dos próprios presos como também de autoridades do Judiciário e M inistério Público, assim como da sociedade civil, que milita em favor dos direitos humanos. Um aspecto a ser ainda pesquisado é se esse regime disciplinar está sendo usado para a construção de uma nova pax prisional. O s governos ameaçam ou efetivamente segregam as lideranças das facções no RDD. A manutenção das lideranças nas unidades prisionais comuns significa que delas se espera que colaborem minimamente com a manutenção da or- 
dem interna, como a redução das mortes entre presos, redução das brigas e mesmo tentativas de fuga.

No entanto são freqüentes as queixas dos presos quanto à permanência nestes locais de segregação mais rígida. Em resposta a essa segregação, grupos no Rio de Janeiro e em São Paulo provocaram ações de enfrentamento direto das autoridades, promovendo alguns atentados. 0 jornal Folha de $S$. Paulo, de 17 de outubro de 2002, noticiava uma série de ações ocorridas nos dias anteriores, que teriam sido promovidas por um grupo criminoso, no Rio de Janeiro, que envolveram uma tentativa de resgate de presos de uma penitenciária, 0 ataque a uma viatura da polícia com a morte de um policial, o lançamento de granadas contra um shopping center, logo em seguida disparos contra o Palácio do Governo do Estado do Rio de Janeiro, ataque a um outro carro da polícia e a uma delegacia. $\mathrm{N}$ a tentativa de fuga da penitenciária de Bangu 3, os presos tinham posse de cinco quilos de explosivos, três fuzis AR-15, cinco pistolas e três granadas. M esmo assim, a fuga foi evitada. Masisso desencadeou uma rebelião.

Nesse mesmo ano, já tinham ocorrido vários outros atentados, sempre atribuídos ao Comando Vermelho, que seria o grupo criminoso que controla o tráfico de drogas em várias regiões do Rio de Janeiro, e que revelaria um certo posicionamento político de enfrentamento das autoridades, buscando pressionar e negociar para que seus principais líderes não sejam mantidos nas prisões de segurança máxima e tenham seus movimentos limitados. As ações anteriores foram igualmente ousadas, como a da madrugada de 3 de março, na qual um comboio de carros de criminosos metralhou uma delegacia de polícia e um outro posto policial, além de dispararem contra alguns carros. Em 16 de maio, dois postos de policiamento comunitário foram alvo de atentados com granadas. Numa outra ação bastante ousada, um comboio de carros de criminosos invadiu uma delegacia de polícia e roubou quatro carros e um ônibus. 
Sociologias, Porto Alegre, ano 8, no 16, jul/dez 2006, p. 274-307

Essas ações e atentados a bomba no Rio de Janeiro tiveram uma outra seqüência em 24 de fevereiro de 2003, quando lojas, ônibus, supermercados foram atingidos. Mais uma vez a polícia atribuía os atentados ao Comando Vermelho e a uma reação de um de seus líderes. ${ }^{12}$ No dia 31 de março de 2003, na cidade do Rio de Janeiro, no espaço de pouco mais de uma hora da madrugada, um coquetel molotovfoi atirado contra a entrada de uma estação do metrô, uma bomba de fabricação caseira foi lançada contra o Hotel Le Meridien e bandidos fizeram um bloqueio numa das principais avenidas para assaltar carrose ônibus. Com a chegada da polícia, um policial foi baleado e morreu. Estas ações, segundo a polícia, teriam sido cometidas em represália à prisão de um líder do Comando Vermelho alguns dias antes. Depois desses atentados no Rio em fevereiro, Fernandinho Beira-Mar, considerado um dos maiores traficantes do Rio de Janeiro, foi transferido para São Paulo, para a Penitenciáira de Presidente Bernardes (que funciona com RDD).

Em novembro de 2003, a polícia atribuiu vários atentados a delegacias e postos policiais ao Primeiro Comando da Capital (PCC), os quais provocaram a morte de dois policiais e vários feridos. Segundo ela, a razão para esses atentados teria sido uma reivindicação não atendida de abrandamento do RDD na Penitenciária de Presidente Bernardes, no interior de São Paulo, onde estavam alguns dos principais líderes deste grupo criminoso.

A antropóloga Alba Zaluar, ao analisar os atentados de 2003 no Rio de Janeiro, sugere que algumas faç̧ões criminosas mais poderosas já se reconhecem como força política, por controlarem áreas territoriais consideráveis da cidade, além de suas populações e de mobilizarem enormes recursos financeiros provenientes principalmente do tráfico de drogas. Segundo ela, essas ações e atentados não expressariam apenas uma atitude desesperada desses grupos em aliviar o confinamento de suas lideranças nos

12 Jornal Folha de S. Paulo, 25 de fevereiro de 2003. 
presídios de segurança máxima, mas também uma pressão para que "o Estado negocie com eles" (Folha de S. Paulo, 17/10/2004). Ela chega mesmo a aproximar a atitude desses grupos à das Farc (Forças Armadas Revolucionárias da Colômbia).

Esta atuação política dos grupos criminosos pode acrescentar um novo aspecto ou tendência ao debate sobre as rebeliões, pois retoma o perfil de enfrentamento com as autoridades, porém não mais no campo exclusivo das prisões, mas também em territórios ampliados sob o seu controle (como os bairros pobres), ou vistos como alvos para uma medida de forças (postos policiais, repartições públicas pontos comerciais, etc.).

\section{Considerações finais}

As rebeliões no Brasil, nos últimos anos, têm mostrado que as duas principais vertentes teóricas voltadas para a compreensão deste fenômeno - a da privação material e a ausência de controle - apresentam limitações que demandam pesquisas mais aprofundadas. 0 artigo procurou apenas levantar algumas dessas limitações e sugerir que haja uma composição dos elementos dessas teorias.

As privações materiais e de toda ordem continuam a ser impostas aos presos no Brasil. Elas constituem um poderoso ingrediente na emergência dos movimentos de revolta dos encarcerados. Porém a maior parte das prisões brasileiras vem funcionando com um mínimo de controle por parte do Estado. Isto significa que muitas atividades quotidianas dentro das prisões são organizadas e dirigidas pelos próprios presos. D ois ou três agentes de segurança são responsáveis por 500,600 ou mais presos, numa evidente demonstração que não dispõem de qualquer meio para impor as regras estabelecidas pela administração prisional. As massas carcerárias ficam, assim, à disposição das lideranças dos grupos mais organizados que ali se encontram. 
Sociologias, Porto Alegre, ano 8, no 16, jul/dez 2006, p. 274-307

Essas lideranças, em muitas prisões, controlam o tráfico interno de drogas, comandam ações criminosas de dentro dos presídiose, para tanto, buscam exercer este poder, sem contestação dos demais grupos e dos presos que são, muitas vezes extorquidos e forçados a assumir crimes que não praticaram. No curso das disputas pelo controle dessas atividades, as rebeliões e as mortes impostas aos desafetos são estratégias para a obtenção da adesão da massa carcerária ou, pelo menos, para a sua conivência com a liderança exercida por determinado grupo.

Esta é hoje uma dimensão nova nas rebeliões dentro das prisões brasileiras que são, muitas vezes, promovidas para firmar a liderança de um grupo sobre a massa carcerária, recompor alianças, posicionar novos líderes. É lógico que este plano horizontal das rebeliões não está imune às interferências da administração, mas o que cabe aqui sugerir como tendência são os motins que não se voltam para demandas específicas para a administração prisional mas que ressignificam, reposicionam as liderançase as acomodações entre os próprios presos.

Num plano vertical, das relações entre os custodiadores e os presos, o crescimento dos grupos organizados parece seguir uma dupla direção. U ma é quando a administração reconhece a ascendência do 'piloto' e das lideranças sobre a massa carcerária e se estabelece um regime de paz, no qual o quotidiano da prisão é efetivamente conduzido pelos presos em troca da não-interferência da administração nos "negócios" dos grupose de suas lideranças. A ocorrência de tentativas de fuga ou de ilegalidades de maior envergadura podem provocar quebras nesta acomodação, o que leva a administração a isolar as lideranças e impor castigos mais severos. Q uando isso ocorre, surge uma atuação cada vez mais 'política' dos grupos organizados de presos, como se indicou acima. Buscam negociar com as autoridades a revogação dessas medidas e, quando os canais são restritos, têm sido promovidos atentados a bomba, assassinatos de policiais e outras auto ridades. 
Fenômeno interessante e que merece novas pesquisas é a construção da identidade desses grupos e de como eles têm servido para aglutinar os presos enquanto força política, em oposição à administração. Pode-se imaginar que, no futuro, torne-se mais robusta esta oposição à administração, na medida em que uma agenda restrita de reivindicações, voltadas para os grupos que lideram no interior das prisões se torne uma agenda coletiva de reivindicações, demandando melhorias no sistema e denunciando irregularidades e ilegalidades. Conspiram contra esta consciência coletiva, no entanto, os jogos de acomodações entre os grupos que lideram os presídios, e suas oportunidades de ganho e de controle sobre a massa, os quai, para se realizarem implicam negociação constante com o staff. Este, ao mesmo tempo, pode tentar quebrar a hegemonia de determinados grupos, como aliás já tem tentado fazer, estimulando a criação de outros grupos criminosos, rivais, que também disputem a liderança no interior das prisões e representem uma alternativa de filiação para os presos.

\section{Referências}

ADAM S, Robert. Prison Riots in Britain and the United States. London: Macmillan Press, 1994.

ADO RNO, Sérgio. Sistema Penitenciário no Brasil: problemas e desafios. Revista USP, São Paulo, vol. 9, p.65-78, 1991.

AD O RNO , Sérgio. Prisões, violência e direitos humanos no Brasil In: PINHEIRO, Paulo Sérgio e GUIM ARÃES, Samuel Pinheiro (orgs.) Direitos Humanos no século XXI. Brasília: Instituto de Pesquisas de Relações Internacionais, Fundação Alexandre de Gusmão, 1998.

ARTIÈRES, Philippe, QUERO, Laurent et ZANCARINI-FO URNEL, M ichelle. Le Groupe D'Information sur les Prisons - archives de lutes, 1970-1972. Paris: Éditions de L'IMEC, 2003. 
Sociologias, Porto Alegre, ano 8, no 16, jul/dez 2006, p. 274-307

CALDEIRA, César. Segurança Pública e Política Penitenciária no Rio de Janeiro: estudo do caso do presídio Ary Franco. Revista Rio de Janeiro, v. 12, p.11-38, janabril, 2004.

CHAU VEN ET, Antoinette, O RLIC, Françoise et BENGUIGUI, Georges. Le Monde des Surveillants de Prison. Paris: PU F, 1994.

CLEM M ER, Donald. The Prison Community. New York: Holt, Rinehart \& Winston, 2nd edn, 1958.

COELHO, Edmundo Campos. A O ficina do Diabo: crise e conflito no sistema penitenciário do Rio de Janeiro. Rio de Janeiro: IU PERJ/ Espaço e Tempo, 1987.

CO O KE, David J. Containing violent prisoners: na analysis of the Barlinnie Special Unit. The British Journal of Criminology, v. 29, n.2, p.129-143, 1989.

DAVIES, William. Prison Riots. The Psychologist, v. 4, n.3, p.120-122, march, 1991.

FAVARD, Jean. Le labyrinthe pénitentiare. Paris: Le Centurion, 1981

FAVARD, Jean. Des Prisons. Paris: Gallimard, 1987.

FISHER, Rosa Maria e ABREU, Sérgio França Adorno de. Análise do Sistema Penitenciário do Estado de São Paulo: o gerenciamento da marginalidade social. São Paulo: Relatório de Pesquisa, CEDEC, 1987.

FISHER, Rosa Maria. Poder e Cultura em Organizações Penitenciárias. Tese de Livre-docência. Faculdade de Economia e Administração da USP. São Paulo, 1989.

FO U CAULT, Michel. Vigiar e Punir: nascimento da prisão. Petrópolis: Vozes, 1987.

GÓ ES, Eda M aria. A Recusa das Grades: rebeliões nos presídios paulistas, 19821986. Dissertação de Mestrado em História, Fac. De Ciências e Letras de Assis, UNESP, 1991.

GOFFMAN, Erving. Manicômios, Prisões e Conventos. São Paulo: Perspectiva, 1974.

HAYNER, Norman S. and ASH, Ellis. The Prisoner community as a social group. American Sociological Review, v. 4, n.3, p.362-369, 1939.

KING, Roy D. and MCDERMONT, Kathkeen. 'My geranium is subversive': some notes on the management of trouble in prison. The British Journal of Sociology, $v$. 41, n.4, p.445-471, 1990. 
LEM GRU BER, Julita. Cemitério dos Vivos: análise sociológica de uma prisão de mulheres. Rio de Janeiro: Achiamé, 1976.

LIM A, Regina Campos. A Sociedade Prisional e suas facções criminosas. Londrina: Edições Humanidades, 2003.

MACCORMICK, Austin H. Behind the Prison Riots. The Annals of American Academy of Political and Social Science, v. 293, p.17-27, 1954.

MCCLEERY, Richard H. Mudança de política na administração de presídios. IN: ETZIO N I, Amitai. O rganizações Complexas: estudo das organizações em face dos problemas sociais. São Paulo: Atlas, p.191-198, 1975.

MCCORKLE, Lloyd W. and KORN, Richard. Ressocialization within walls. The Annals of the American Academy of Political and Social Science, 293:88-98, 1954.

MINAS GERAIS. SECRETARIA DE ESTADO DO PLANEJAMENTO E COO RDENAÇÃO GERAL. FUNDAÇÃO JO ÃO PINHEIRO. Caracterização da população prisional. Minas Gerais e Rio de Janeiro. Belo Horizonte: Fund. João Pinheiro, mimeo, 1984.

M O NTGO M ERY, Reid H . \& CREWS, Gordon A A History of Correctional Violence: an examination of reported causes of riots and disturbances. American Correctional Association, 1998.

PAIXÃO, Antonio Luiz. Crime, Controle Social e Consolidação Democrática: as metáforas da cidadania. In: REIS, F. W. e O 'D O N NELL, G. (orgs.) A Democracia no Brasil, D ilemas e Perspectivas. São Paulo: Vértice, p.168-199, 1985. $\overline{1} 987$

Recuperar ou punir? Como o Estado trata o criminoso. São Paulo: Cortez,

PINHEIRO, Paulo Sérgio e BRAUN, Eric. Democracia versus Violência: reflexões para a Constituinte. Rio de Janeiro: Paz e Terra, 1986.

RAM ALHO, José Ricardo. Mundo do Crime: a ordem pelo avesso. Rio de Janeiro: Graal, 1979.

RIOS, José Arthur. M otins em prisões: seus fatores e possibilidades de preveni-los. Revista da Escola do Serviço Penitenciário, Porto Alegre, v.1, p. 42-49, 1989.

RO CHA, Luís Carlos da. A Prisão dos Pobres. Tese de D outoramento, Instituto de Psicologia da Universidade de São Paulo, 1994. 
Sociologias, Porto Alegre, ano 8, no 16, jul/dez 2006, p. 274-307

SALLA, Fernando. As Prisões em São Paulo, 1822-1940. São Paulo: AnnablumeFapesp, 1999.

- Casa de Detenção de São Paulo - passado e presente. Revista Brasileira de Ciêências Criminais, São Paulo. v. 32, p.213-220, out./dez, 2000.

. Rebeliões nas Prisões Brasileiras. Serviço Social e Sociedade, São Paulo, v. 67, p.18-37, set., 2001.

SHRAG, Clarence. Leadership among prison inmates. American Sociological Review, v. 19, n.1, p.37-42, 1954.

SO UZA, Percival de A Prisão: história dos homens que vivem no maior presídio do mundo. São Paulo: Alfa-Ô mega, 2a. Edição,s.d..

SPARKS, J.R. e BOTTO MS, A E. Legitimacy and order in prisons. The British Journal of Sociology, v. 46, n. 1, p. 45-62, 1995.

SYKES, Gresham M. A Corrupção da Autoridade e a Reabilitação, IN: ETZIO NI, Amitai Organizações Complexas: estudo das organizações em face dos problemas sociais. São Paulo: Atlas, p.191-198, 1975.

SU LLIVAN, Larry E. The Prison Reform Movement: forlorn hope. Boston: Twayne Publishers, 1990.

THOM PSO N, Augusto F. G. A Q uestão Penitenciária. Petrópolis: Vozes, 1976.

USEEM , Bert \& KIM BALL, Peter A . A Theory of Prison Riots. Theory and Society, v. 16 , p. $87-122,1987$

. States of Siege: U.S. prison riots, 1971-1986. New York: O xford U niversity Press, 1991.

WACQ UANT, Loïc. La tentation Pénal en Europe. Actes de la recherche en sciences sociales, v. 124, p. 3-6, 1998.

L'ascension de l'état pénal en Amérique. Actes de la recherche en sciences sociales, v. 124, p. 7-26, 1998b.

. Les Prisons de la Misère. Paris: Éditions Raisons d'Agir, 1999.

WEINBERG, S. Kirson. Aspects of the prison's social structure. The American Journal of Sociology, v. 47, n.5, p. 717-726, 1942. 
Sociologias, Porto Alegre, ano 8, ㄲo 16, jul/dez 2006, p. 274-307

\section{Resumo}

O objetivo deste artigo é analisar o perfil das rebeliões no sistema carcerário do Brasil, desde a década de 70, recuperando, para tanto, a reflexão produzida sobre estes eventos na França, nos Estados U nidos e no Reino U nido. 0 artigo tem por argumento principal que as rebeliões nas prisões brasileiras, nos últimos quinze anos, estão associadas tanto às condições degradadas de encarceramento como às deficiências do Estado em exercer o controle sobre o quotidiano prisional, permitindo que grupos criminosos organizados exerçam o poder sobre a massa carcerária, utilizando-se das rebeliões para a eliminação dos inimigos e o fortalecimento de sua posição de domínio frente ao staff prisional.

Palavras-chave: prisão, rebeliões, mortes, gangues, sistema penitenciário.

Recebido: 07/04/06

Aceite final: 06/06/06 


\section{Prison riots: new meanings after the Brazilian experience}

\section{Fernando Salla}

The aim of this article is to examine the profile of riots in Brazil's prison system since the 1970s, reviewing what has been produced on those events in France, the U nited States, and the U nited Kingdom. The article's main argument is that riots in Brazilian prisons in the last fifteen years have been associated both to decaying prison conditions and the State's problems to exert control over the prison's everyday life, thus allowing organized crime groups to exert power over the mass of inmates, who use riots to remove enemies and strengthen their position of domination before prison staff.

Key words: prison, riots, deaths, gangs, prison system. 